\title{
Age structure of coenopopulation of Fragaria vesca $L$. in the natural and transformed habitats
}

\author{
Natalya Romanova $^{1 *}$, and Irina Olefirenko ${ }^{1}$ \\ ${ }^{1}$ Kemerovo State University, Kemerovo, 650000, Russia
}

\begin{abstract}
The article describes the types of ontogenetic spectra of Fragaria vesca $\mathrm{L}$. growing in the natural and broken habitats. It shows that the character of age spectra did not differ and invariably remained in both ecotopes for the years of the research. The old individuals were frequently found in an atypical habitat than in natural one. The nature of self-maintenance of coenopopulation of a species is typical for its biomorph and does not depend on the place of growth.
\end{abstract}

\section{Introduction}

The populational and ontogenetic method of researches gained wide popularity because the various indicators which characterize development and the state of a species are considered with its help in the different phytocenotic conditions [1].

The purpose of this work is to reveal the features of age structure of coenopopulation of Fragaria vesca L. in the natural and broken habitats.

\section{Materials and methods}

Fragaria vesca L. is a perennial, polycarpic, ground-stoloniferous plant of the Rosaceae family [2]. The wild strawberry is an ecologically plastic species [3, 4]. It actively acclimatizes anthropogenically broken habitats revealing itself as a typical explerent [5].

The researches were conducted near the township Privolniy in Kemerovo district in 2015-2017 in the first decade of July. Two coenopopulations of wild strawberry were chosen: CP1 is a control one (natural typical habitat) located in the birch forest, rich in herbs and cereal, and occupied the area of 2-2.5 thousand $\mathrm{m}^{2}$, and CP2 is an experimental one (transformed atypical habitat) on the slope of the southern aspect of the railway dump of rock with the area of 4 thousand $\mathrm{m} 2$ with forming cereal and rich in herbs phytocenosis. The distance between the studied coenopopulations is $700 \mathrm{~m} \mathrm{[6].}$

One counted the vegetative and generative rosettes on the sampling quadrats of $1 \mathrm{~m}^{2}$. There were 30 sampling quadrats grounded in the forest and on the dump. The age conditions of individuals were defined in coenopopulations and the age spectra were interpreted on S.A. Dubrovnaya [4]. The age spectra were assembled with the use of the

\footnotetext{
*Corresponding author: chatn@yandex.ru
} 
standard populational and ontogenetic techniques for the definition of ratios of different age groups in coenopopulations.

\section{Results}

The analysis of ontogenetic spectra of 2015 showed that coenopopulations were normal incomplete during the research. This feature is noted for the wild strawberry growing in the broken and undisturbed habitats of the European part of the areal [4].

$\mathrm{CP} 1$ was characterized by a left-sided age spectrum with the absolute dominance of virginile individuals (68\%) (fig. 1a). The obtained spectrum is similar to S.A. Dubrovnaya's one [4] for coenopopulations of wild strawberry growing in the conditions of low illumination.

CP2 was characterized by a left-sided age spectrum $(45 \%$ of individuals of pregenerative fraction) (fig. 1b). At the same time the part of middle-aged generative individuals made $28 \%$ and the part of post-generative individuals was less than $1 \%$.

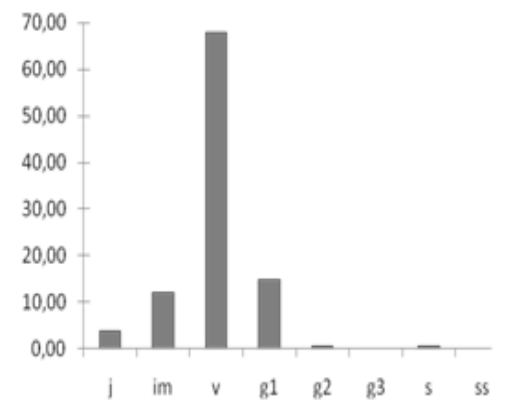

a

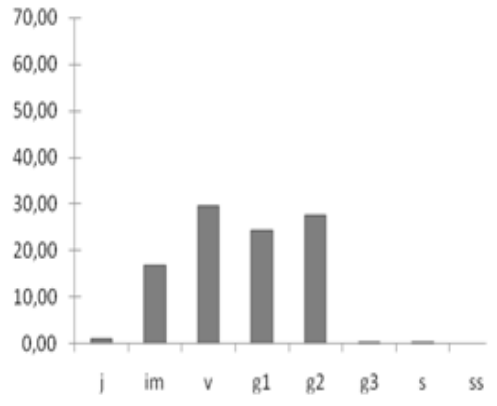

b

Fig. 1. Age structure of $F$. vesca in CP1 (a) and CP2 (b), 2015. Notes: x-direction - age conditions, y-direction - part of individuals, $\%$.

The coenopopulations were also normal incomplete in 2016. There were no senile individuals in the age spectra of wild strawberry on the dump and the individuals of old generative, sub-senile and senile age were absent in the forest.

The age spectrum of CP1 was characterized as left-sided one with the greatest parts of individuals of the pre-generative period (immature and virginile). The part of middle-aged generative individuals made $25 \%$ (fig. 2 a). The old individuals were absent.

The age spectrum of CP2 was characterized as left-sided with the dominance of immature, virginile and young generative rosettes (fig. 2b). In the work by L.B. Zaugolnova (1994) and S. A. Dubrovnaya [4], the spectra like those obtained by us for the control are called bimodal. The part of middle-aged generative individuals made $20 \%$ and about $8 \%$ of post-generative ones. 


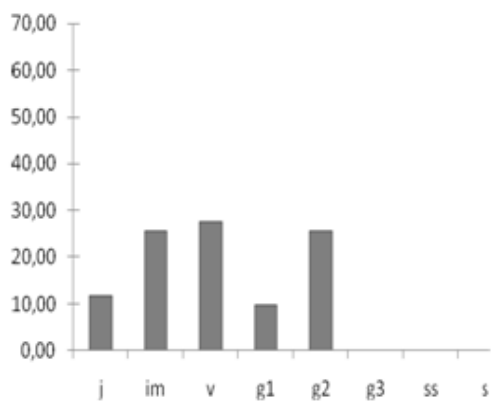

a

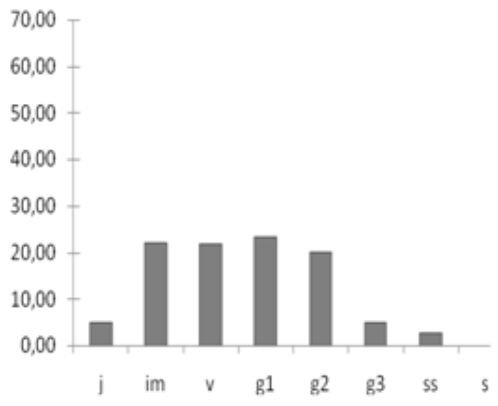

$\mathrm{b}$

Fig. 1. Age structure of $F$. vesca in CP1 (a) and CP2 (b), 2016. The same notes as fig.1.

In the analysis of ontogenetic spectra of 2017, we revealed that coenopopulations were normal incomplete as well as in previous years. There were no senile individuals in transformed habitat and there were no old generative and senile ones in natural habitat.

CP1 was characterized by a left-sided age spectrum with high content of immature $(28 \%)$ and virginile (41\%) individuals. The part of generative individuals made $13 \%$ and the part of post-generative individuals was $15 \%$ (fig. $3 \mathrm{a}$ ).

The age spectrum of CP2 was also left-sided (51\% of individuals of pre-generative fraction) (fig. 3b). At the same time the part of generative individuals made $48 \%$ and the part of post-generative individuals was about $1 \%$.

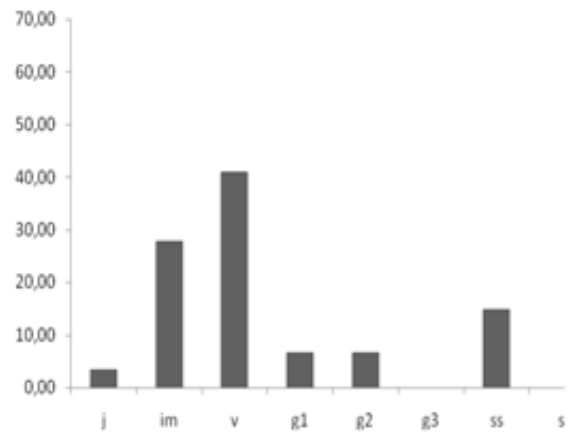

a

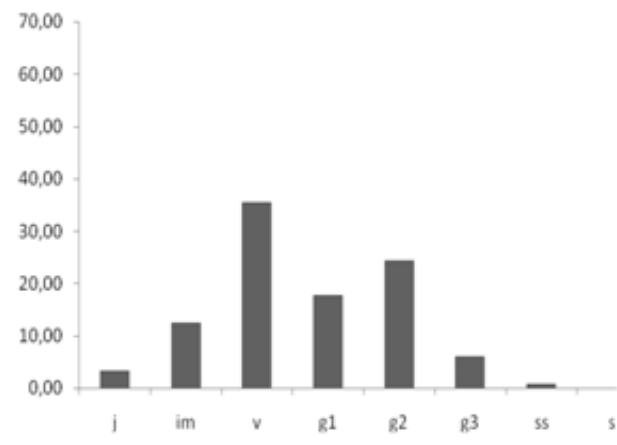

$\mathrm{b}$

Fig. 3. Age structure of $F$. vesca in CP1 (a) and CP2 (b), 2016. The same notes as fig.1.

\section{Discussion}

The coenopopulations of $F$. vesca of various ecotopes were characterized as normal incomplete that corresponds to the literature data. The type of ontogenetic spectrum of wild strawberry in control and experimental coenopopulations was left-sided and did not change by years and by habitat type as well. Our results do not altogether agree with the data of other authors. For example, S.A. Dubrovnaya [4] obtained a left-sided spectrum for coenopopulations of $F$. vesca growing in the European part in the conditions of low 
illumination and she obtained bimodal spectrum in the open habitats. However, T.P. Larkina has the results corresponding to ours after conducting similar researches in the South Ural [7].

At the same time in days of the research, the ratio of rosettes of various age conditions varied in the spectra. In certain years, the dominance of virginile and generative individuals was noted in the natural and transformed habitats. The juvenile individuals were very few in both coenopopulations $(2-12 \%)$ as well as the old ones $(0-15 \%)$. It should be noted that old individuals are often found in the coenopopulation on a dump slope.

The character of age spectra of the studied coenopopulations of $F$. vesca indicates the mixed type of their self-maintenance with the dominance of vegetative one that corresponds to a vital form of the species.

\section{References}

1. V.N. Ilyina, Samarian Luka: Reg. and Glob. Ecol. Probl., 19, 99 (2010)

2. Ontogenetic atlas of medicinal plants (MarSU, Yoshkar-Ola, 1997)

3. L.G. Dobrenkova, Physiological features of strawberry resistance to drought and salinity (LGU, Leningrad, 1978)

4. S.A. Dubrovnaya, Structure of natural wild strawberry populations: Fragaria vesca L. (MGU, Yoshkar-Ola, 2000)

5. J. Philip Grime, S. Pierce, The Evolutionary Strategies that Shape Ecosystems (WileyBlackwell, Chichester, 2012)

6. N.G. Romanova, Problems of botany of south Siberia and Mongolia (AGU, Barnaul, 2015)

7. L.B. Zaugolnova, Struct. of Seed Plant Pop. and Probl. of Their Monit., 70 (1994)

8. T.P. Larkina, Perm. Agr. Rep. 2, 116 (2017)

9. J. Schulze, R. Rufener, A. Erhardt, P. Stoll, PE 54, 369 (2012) 